\title{
The Role of Risk Factors (Onset - Hospitalization, Onset - Surgery, Increase in Pulse, Systolic Blood Pressure) on Death in Gastric Perforation
}

\author{
Faisal Armi Lubis ${ }^{1}$, Sarup Singh ${ }^{1 *}$ \\ ${ }^{1}$ Department of Surgery, Faculty of Medicine, Universitas Sriwijaya, Indonesia \\ *Correspondence Author Email: sarupsingh@gmail.com
}

\begin{abstract}
Introduction. Gastric perforation is the second most common complication due to peptic ulcer after bleeding where the risk of mortality in patients who have received surgical treatment is still high. The factors that have the greatest influence on the death of the patient are old age and the time span of handling more than 24 hours. This study aims to determine the relationship between risk factors (onset - hospitalization, onset - surgery, increased pulse, decreased systolic blood pressure) on the death of gastric perforation patients undergoing surgery at Dr. General Hospital Mohammad Hoesin Palembang.
\end{abstract}

Methods: An observational analytic study with a case-control study design was carried out from August to October 2017 at the Dr. General Central Hospital Mohammad Hoesin (RSMH) Palembang. There were 90 respondents consisting of 30 sample groups with death cases and 60 sample groups with life control. The relationship between independent and dependent variables was analyzed by Chi Square test while risk factors that play a role in death in gastric perforation patients who performed surgery were analyzed with the Logistic Regression test. Data analysis uses SPSS version 18.0.

Results. There was a significant relationship between increased pulse (OR = 11,227 CI95\% 3,92332,129; $\mathrm{p}=0,000)$, onset - MRS (hospital admission) $(\mathrm{OR}=4,125 \mathrm{CI} 95 \%$ 1,579-10,773; $\mathrm{p}=$ $0,006)$ and onset - surgery $(\mathrm{OR}=3,786 \mathrm{CI} 95 \%$ 1,267-11,308; $\mathrm{p}=0.029)$ on the death of a gastric perforation patient undergoing surgery. With the Logistic Regression test, an increase in pulse and 


\section{SSS SRIWIJAYAJOURNAB OFSURGERY}

onset - hospital admission was significantly related to the death of a gastric perforation patient undergoing surgery.

Conclusion. It can be concluded that the increase in pulse and onset of hospital admission are risk factors that contribute to the death of gastric perforation patients who undergo surgery.

Keywords.Risk factors, postoperative mortality, gastric perforation, death risk

\section{Introduction}

Gastric perforation is the second most common complication due to peptic ulcer after bleeding. ${ }^{1}$ Clinical features in patients with gastric perforation are sometimes nonspecific, so most patients present with symptoms and signs of peritonitis and even sepsis which results in poor outcome. The risk of high mortality remains found in patients who have received surgical treatment, evidenced by $3-40 \%$ mortality found in patients who received surgical treatment. ${ }^{2}$

In the United States there are 500,000 new cases with a diagnosis of peptic ulcer. ${ }^{3}$ This complication is a complication that has a high enough rate in causing the risk of death. In Europe reported $23.5 \%$ of cases of death due to gastro intestinal complications are the result of gastric perforation. ${ }^{4}$ In Indonesia a study of the incidence of gastric perforation at the Regional General Hospital Dr. Moewardi Solo for 1 year, from January to December 2007, there were 27 cases of peritonitis due to gastric perforation, 19 cases were operated on, $12(63 \%)$ cases were cured 7 $(37 \%)$ cases died after surgery due to sepsis. ${ }^{5}$

There have been many studies conducted to examine risk factors that affect mortality in patients, including age, systemic condition of the patient, and time span of medical treatment. ${ }^{6}$ In general, gastric perforation shows variability in combination between clinical symptoms of peritonitis, radiological features, laboratory, and intraoperative findings. From the research conducted, a scoring system was formulated to predict patient outcomes.

So far there are several scoring systems such as ASA-score, MPI-score, Jabalpur-score and Boey-score which have become standard around the world. From several studies conducted, different research results were obtained about the accuracy of the scoring system as a predictor of patient outcomes, it might be due to differences in standards and quality of patient services in each 


\section{STS SRIWIJAYAJOURNAB OFEURGERY}

region or country. Boey-score is stated as a simple and specific scoring system to be applied to patients with gastric perforation, it is supported by research which states that the Boey score is a scoring system that has validity with $\rho<0.001$. $^{7,8}$

In 2015, a study of risk factors for morbidity and mortality in black African patients undergoing surgery due to gastric perforation. The results show that the delay in medical treatment and the time span of medical treatment has a very significant effect on the risk of death. In addition to these factors, the increased pulse also has the same high validity as the delay in medical treatment as one of the risk factors for death in gastric perforation cases. ${ }^{4,9-12}$

At the Dr. Moh. Hoesin Palembang mortality rate from gastric perforation in 2013 was $39 \%$. The factors that have the greatest influence on the death of the patient are old age and the time span of handling more than 24 hours. This could be due to the lack of facilities in regional hospitals and also the distance, the time needed to refer patients to the RSUP Dr. Moh. Hoesin Palembang.

This study was intended to explore the role of risk factors in the form of hospitalization onset, surgery onset, increased pulse, and decreased systolic blood pressure on outcome of patients with gastric perforation. These risk factors have never been explored, related to the outcome of gastric perforation patients.

\section{Methods}

The design of this study was observational analytic research with case control study design. Research subjects (30 case groups and 60 control groups) were all patients with a diagnosis of gastric perforation based on history, physical examination, laboratory examination, radiology treated at RSUP Dr. M. Hoesin Palembang, and fulfilled the inclusion and exclusion criteria. The inclusion criteria for case groups were all adult patients who died from gastric perforation and had a complete medical record status (history taking, clinical examination, radiological examination). Criteria for inclusion in the control group were all adult patients with a diagnosis of gastric perforation that remained alive, had complete medical record status, diagnoses were established based on history, clinical examination, radiological examination, patients remained alive until they were declared allowed to return from Dr. Hospital. Moh.Hoesin Palembang. Exclusion criteria are patients with gastric perforation due to other causes (cancer, foreign bodies, typhoid), gastric 


\section{STS SRIWIJAYAJOURNAB OFEURGERY}

perforation patients due to criminal acts or accidents. Sampling is done by matching based on sex and stratification based on age. Specifically the control group is usually taken in accordance with the selection of cases on the same day.

Assessment of hospital admission onset is assessed by looking at medical records, at the history of the time interval since complaints are felt to be more severe until patients are registered in the Emergency Department and erect diagnosis of gastric perforation, grouped $>24$ hours and $\leq$ 24 hours. The onset of surgery was assessed by looking at medical records, the time intervals from the patient was diagnosed with gastric perforation until operative action, grouped ,12 hours and $<12$ hours. The increase in pulse rate was assessed by looking at medical records, heart rate pulses over 100x / minute obtained from the patient's medical record, grouped dikel100 beats / minute and $<100$ beats / minute. Decreased systolic blood pressure was assessed by looking at medical records, the results of blood pressure measurements using mercury blood pressure meters with persistent hypotension obtained from medical records, grouped $\leq 90 \mathrm{mmHg}$ and $>90 \mathrm{mmHg}$.

Univariate data analysis aims to determine the characteristics of patients who experienced postoperative death due to gastric perforation. Presented in the form of a diagram along with its interpretation. Bivariate analysis aims to determine the significance of the relationship between the independent variable and the dependent variable. Bivariate analysis was performed using Chi Square to test the significance of hypotheses. Chi Square Test was determined with an $\alpha$ value of 0.05. To find out which risk factors play the most role using logistic regression. Data analysis using IBM SPSS Version 23.

\section{Results}

From 90 respondents, the mean age of gastric perforation patients was $59.01 \pm 12.98$ years with an age range of 21-84 years. In the group with death outcomes the mean age of gastric perforation patients was $62.6 \pm 10.388$ years with an age range of 33-80 years while in the group with life outcomes the average age of gastric perforation patients was $57.22 \pm 13.829$ years with an age range of 21-84 year. With the independent $T$ test a probability of 0.063 ( $\mathrm{p}>0.05)$ means that there is no age difference between the two groups.

The majority of gastric perforation patients were male $(75.6 \%)$ while those who were female were $24.4 \%$. In the group with the outcome of death of patients with male sex were as much 


\section{STS SRIWIJAYA JOURNABOFEURGERY}

as $66.7 \%$ and women as much as $33.3 \%$ while in the group with the outcome of life of patients with male sex were as much as $80 \%$ and women as much as $20 \%$. With the Chi-Square test the probability is 0.260 ( $p>0.05$ ) which means that there is no gender difference between the two groups.

Table 1. Demographic Characteristic of Subjects

\begin{tabular}{lccc}
\hline \multicolumn{1}{c}{ Demographic Characteristic } & Died & Alive & p value \\
\hline Age (years), mean \pm SD & $62,6 \pm 10,388$ & $57,22 \pm 13,829$ & $0,063^{*}$ \\
Sex, $\mathrm{n}(\%)$ & & & \\
- $\quad$ Male $\quad 20(66,7)$ & $48(80 \%)$ & $0,260^{* *}$ \\
- $\quad$ Female & $10(33,3)$ & $12(20 \%)$ & \\
\hline * Independent T test $, \mathrm{p}=0,05$ & & & \\
$* *$ Chi Square test $, \mathrm{p}=0,05$ & & &
\end{tabular}

There is a significant relationship between increased pulse and death outcomes in patients with gastric perforation where patients with increased pulse ( $\geq 100$ beats / $\mathrm{min}) 11,227 \mathrm{x}$ are significantly more at risk of death outcomes in gastric perforation patients than patients without an increase in pulse $(<100$ beats / min ). There is a significant relationship between MRS onset and death outcomes in patients with gastric perforation where patients with MRS onset $\geq 24$ hours $4.125 \mathrm{x}$ are significantly more at risk of death outcomes in patients with gastric perforation than patients with MRS onset $<24$ hours. There is a significant relationship between onset - surgery with death outcomes in patients with gastric perforation where patients with onset - surgery $\geq 12$ hours $3,786 \mathrm{x}$ are significantly more at risk of death outcomes in patients with gastric perforation compared with patients with onset - surgery $<12$ hours. 


\section{STS SRIWIJAYA JOURNAB OFEURGERY}

Table 2. Clinical Characteristic of Subjects

\begin{tabular}{|c|c|c|c|c|c|}
\hline \multirow[t]{2}{*}{ Characteristic } & \multicolumn{2}{|c|}{ Outcome } & \multirow[b]{2}{*}{ Total } & \multirow[b]{2}{*}{$\begin{array}{c}\mathrm{PR}^{*} \\
(\mathrm{CI} 95 \%)\end{array}$} & \multirow[b]{2}{*}{$\begin{array}{c}p \\
\text { value* }\end{array}$} \\
\hline & Die & Alive & & & \\
\hline \multicolumn{6}{|l|}{ pulse } \\
\hline - $\geq 100$ times/min & 19 & 8 & 27 & 11,227 & 0,000 \\
\hline - $<100$ times/min & 11 & 52 & 63 & $(3,923-32,129)$ & \\
\hline \multicolumn{6}{|l|}{ Systole } \\
\hline - $\leq 90 \mathrm{mmHg}$ & 10 & 11 & 21 & 2,227 & 0,186 \\
\hline - $\quad>90 \mathrm{mmHg}$ & 20 & 49 & 69 & $(0,818-6,066)$ & \\
\hline \multicolumn{6}{|l|}{ Hospitalization Onset } \\
\hline - $\geq 24$ hours & 22 & 24 & 46 & 4,125 & 0,006 \\
\hline - $\quad<24$ hours & 8 & 36 & 44 & $(1,579-10,773)$ & \\
\hline \multicolumn{6}{|l|}{ Operation Onset } \\
\hline - $\geq 12$ hours & 10 & 7 & 17 & 3,786 & 0,029 \\
\hline - $<12$ hours & 20 & 53 & 73 & $(1,267-11,308)$ & \\
\hline
\end{tabular}

Increased pulse and MRS onset significantly influence death outcomes in patients with gastric perforation in which patients with increased pulse ( $\geq 100$ beats / min) are $10.5 \mathrm{x}$ more risky than patients without pulse increases $(<100$ beats $/ \mathrm{min})$ significantly $(\mathrm{OR}=10,500$, $\mathrm{p}$ value $=$ 0,000 ) while patients with MRS onset $\geq 24$ hours have a $3.5 \mathrm{x}$ greater risk than patients with MRS onset $<24$ hours significantly $(\mathrm{OR}=3.504, \mathrm{p}$ value $=0.029)$. Patients with a decrease in systolic blood pressure ( $\leq 90 \mathrm{mmHg}$ ) had a risk of $2.038 \mathrm{x}$ more than patients with a decrease in TDS of death in patients with gastric perforation but were not significant $(\mathrm{OR}=2.308$, $\mathrm{p}$ value $=0.258)$. Likewise, patients with onset - surgery $\geq 12$ hours had a risk of $3.423 \mathrm{x}$ compared with patients with 


\section{SSS SRIWIJAYA JOURNAL OFSURGERY}

onset - surgery $<12$ hours of death in patients with gastric perforation but were not significant (OR $=3.423, \mathrm{p}$ value $=0.073$ ).

Table 3. Risk Factors That Role Against Death Output In Gastric Perforation Patients

\begin{tabular}{|c|c|c|c|c|}
\hline \multirow{2}{*}{ Variable } & \multicolumn{2}{|c|}{ Unadjusted* } & \multicolumn{2}{c|}{ Adjusted** } \\
\cline { 2 - 5 } & OR & $p$ value & OR & $p$ value \\
\hline Pulse Increase & 11,227 & 0,000 & $\mathbf{1 0 , 5}$ & $\mathbf{0 , 0 0 0}$ \\
Hospitalization Onset & 4,125 & 0,006 & $\mathbf{3 , 5 0 4}$ & $\mathbf{0 , 0 2 9}$ \\
Operation Onset & 3,786 & 0,029 & 3,423 & 0,073 \\
Systolic decrease & 2,227 & 0,186 & 2,038 & 0,258 \\
& & & & \\
\hline
\end{tabular}

*Chi Square test

** Regression Logistic test

\section{Discussion}

In this study the mean age of patients with gastric perforation with an outcome of death was greater than that of patients with gastric perforation with a live outcome after surgery. However, the statistical analysis showed that there were no differences in age and sex between patients with gastric perforation with outcomes of death and life. This means that both groups are comparable and there is no effect of age and sex with gastric perforation outcomes.

In this study, of the 30 respondents who died there were 19/30 (63.3\%) patients with an increase in pulse ( $\geq 100$ beats / $\mathrm{min})$. With statistical analysis it was found that patients with gastric perforation with increased pulse ( $\geq 100$ beats / min) 11,227 x were more at risk of death than patients without an increase in pulse ( $<100$ beats / $\mathrm{min}$ ) significantly (PR $=11,227$ CI95\% 3,923$32,129 ; \mathrm{p}=0,000)$. A study conducted by Gona et al in 2016 found that $72 \%$ of patients with gastric perforation who died had an average pulse 110 times per minute and with statistical analysis the results showed patients with gastric perforation with increased pulse ( $\geq 100$ times / minute) 2.4 times more at risk died compared to patients without a significant increase in pulse rate $(<100$ beats $/ \mathrm{min})(\mathrm{PR}=2.4 \mathrm{CI} 95 \% 1.1-4.9 ; \mathrm{p}=0.020) .{ }^{4}$ In addition, 10/30 gastric perforation patients 
were found dead ( 33.3\%) experienced a decrease in systolic blood pressure (TDS ( $\leq 90 \mathrm{mmHg})$. With statistical analysis it was found that patients with gastric perforation with a decrease in systolic blood pressure (TDS ( $\leq 90 \mathrm{mmHg}$ ) 2,227 x were more at risk of dying than patients without a decrease in systolic blood pressure (TDS $(\leq 90 \mathrm{mmHg})$ but not significant (PR $=2.227 \mathrm{CI}$ 95\% 0.818-6.066; $\mathrm{p}=0.186)$.

The presence of bacteria in the peritoneal cavity stimulates the influx of acute inflammatory cells. The stomach and internal organs tend to localize the site of inflammation, forming phlegmons (this usually occurs in perforation of the large intestine). Hypoxia induced in the area facilitates the growth of anaerobic bacteria and causes weakening of bactericidal activity of granulocytes, which leads to increased phagocyte granulocyte activity, cell degradation, fluid hypertonicity forming abscesses, osmotic effects, more fluid flow to the abscess area, and enlarged abdominal abscesses. If this condition is not treated immediately it will cause a septic shock condition, which is marked by an increase in pulse rate with less content and stress, followed by a decrease in blood pressure, multi-organ failure and lead to death. ${ }^{13}$ In addition, stimulation of the peritoneum causes tenderness and muscular defense. Deafness can be lost because of the free air under the diaphragm. Intestinal peristalsis decreases until it disappears due to temporary intestinal paralysis. When bacterial peritonitis has occurred, the patient's body temperature will rise and tachycardia occurs, hypotension, and the patient looks lethargic due to toxic shock. Peritoneal stimulation causes pain in every movement which causes a shift in the peritoneum with the peritoneum. $^{14-17}$

In this study, 22/30 gastric perforation patients with MRS onset $\geq 24$ hours died after surgery $(73.3 \%)$. With statistical analysis the results showed that patients with gastric perforation with MRS onset jam 24 hours 4.125 times were more at risk of death than patients with MRS onset $<24$ hours significantly $(P R=4.125$ CI95\% 1.579-10.7773; $\mathrm{p}=0.006)$. Another study stated that patients with gastric perforation with MRS onset $\geq 72$ hours found $2.6 \times$ higher risk of death than patients with MRS onset <72 hours significantly $(\mathrm{PR}=2.6 \mathrm{CI} 95 \% 1.2-5.7 ; \mathrm{p}=0,001) .{ }^{18}$ Other studies have found that the length of patient referral time (> 48 hours since the symptoms of epigastric pain) and the presence of signs and symptoms of shock, are risk factors that increase the incidence of postopertif morbidity in patients with duodenal ulcer with perforation. However, the 


\section{SSS SRIWIJAYA JOURNAB OP SURGERУ}

difference between this study and that of Akhtar et al. differences in MRS onset and type of perforation. ${ }^{19}$ In addition 10/30 patients with gastric perforation with onset - surgery $\geq 12$ hours died after surgery (33.3\%). With statistical analysis the results showed that patients with gastric perforation with onset - surgery $\geq 12$ hours $3,786 \mathrm{x}$ were more at risk of death than patients with onset - surgery <12 hours significantly $(P R=3,786$ CI95\% 1,267-11,308; $\mathrm{p}=0.029)$. Research conducted by Gona et al found that patients with gastric perforation with a 24-48 hour preoperative onset of $3.8 \times 3.8$ were more at risk of death than patients with a significant 24 hour preoperative onset $(\mathrm{PR}=3.8 \mathrm{CI} 95 \%$ 1.7-8.5; $\mathrm{p}=0.001) .{ }^{20}$ From a multivariate analysis (Logistic Regression), the result is an increase in pulse and hospital onset is a risk factor for death after surgery in patients with gastric perforation. This explains that although surgery is performed faster or there is a decrease in systolic blood pressure, the risk of death is still great if there has been an increase in pulse before surgery and the time of referral. Things will get worse if onset of hospital admission has been more than 24 hours since complaints being more intense before diagnosis of gastric perforation has been determined.

\section{Conclusion}

Increased pulse ( $\geq 100$ beats / $\mathrm{min}$ ) and hospital onset ( $\geq 24$ hours) are the most important risk factors in mortality outcomes in patients with gastric perforation.

\section{References}

1. Chalya PL, et All. Clinical profile and outcome of surgical treatment of surgical treatment of perforated peptic ulcer in northwestern Tanzania: A Tertiay hospital experice. World. Journal of Emergency 2011.

2. Thorsen K, Soreide J, Scoring systems for outcome prediction in patients with perforated peptic ulcer.sacandavian journal of traua, resuscitation and emergency medicine 2013, $21: 25$ 


\section{STS SRIWIJAYA JOURNAB OFEURGERY}

3. Ramakrishnan K,et all. Peptic ulcer disease, University of oklahoma health sciences center, oklahoma city. Am Fam Physician 2007.

4. Gona, Soro Kountele, et al. Postoperative Morbidity and Mortality of Perfrated Peptic Ulcer: Retrospective Cohort Study of Risk Factors among Black Africans in Cte d'Ivore. Journal of Gastroenterology Research and Practice.Hindawi. Dec 2015.

5. Iskandar $\mathrm{H}$, et all.Hubingan antara Abdominal perfusion presure (APP) dengan outcome post operasi perforasi gaster. Universitas Sebelas Maret Surakarta, 2015.

6. Jasneet Singh,et all. Improving outcome in perforated peptic ulcer emergency surgery by Boey Scoring, departement of surgery, Safdarjung Hospital, New Delhi, India 2016.

7. D.L Buck, et all. Surgical delay is a critical determinant of survival in perforated peptic ulcer. British journal of surgery society $2013 ; 100: 1045-1049$

8. Svanes, Cecilie et al. Adverse Effects of Delayed Treatment for Perforated Peptic Ulcer. Annals of Surgery 1994; 220 168-175.

9. Moore, Keith L.and Arthur F Dalley. Clinically Oriented Anatomy.7th edition. Lippincot Williams\& Wilkins.2013: 226,231-,236.

10. Louise Tucker. Anatomy and Physiology.5th edition.EMS Publishing, 2015; Chapter 11. The Digestive System 315-372.

11. Wallace JL. Prostaglandins, NSAIDS, and Gastric Mucosal Protection. 2008 Oct;88 C4: 1547-65.

12. Schubert ML, Peura DA. Control of gastric acid secretion in health and disease.Gastroenterology. 2008 Jun. 134(7):184260

13. Yuan XG, Xie C, Chen J, Xie Y, Zhang KH, Lu NH. Seasonal changes in gastric mucosal factors associated with peptic ulcer bleeding. Exp Ther Med. 2015 Jan. 9(1):125130

14. Lau WY, Leow CK. History of perforated duodenal and gastric ulcers. World J Surg. 1997 Oct. 21(8):890-6.

15. Langell JT, Mulvihill SJ. Gastrointestinal perforation and the acute abdomen. Med Clin North Am. 2008 May. 92(3):599-625.

16. Cai S, García Rodríguez LA, MassóGonzález EL, HernándezDíaz S. Uncomplicated peptic ulcer in the UK: trends from 1997 to 2005. Aliment Pharmacol Ther. 2009 Nov15.30 (10) :1039-1048 


\section{SSS SRIWIJAYAJOURNAB OFEURGERY}

17. Sjamsuhidayat R, Jong WD. Lambung dan Duodenum dalam Buku Ajar Ilmu Bedah. Edisi 2.2005.Jakarta : Penerbit Buku Kedokteran EGC.hal 542-560

18. Doherty, GM. Current Surgical Diagnosis and Treatment, In: Perforated Peptik Ulcer 12th ed. 2003. USA : McGraw-Hill. p. 528-529.

19. Brunicardi FC etc. Schwarts's Principles of surgery, inPeptik Ulcer disease.8th ed. 2005. USA: McGraw-hill.p934-968.

20. Crofts TJ, Park KG, Steele RJ. A randomized trial of nonoperative treatment for perforated peptic ulcer. N Engl J Med. 1989 Apr 13. 320(15):970-3. 